\title{
Postnatal Changes in Renal Glomerular Blood Flow Distribution in Puppies
}

\author{
Hermann Olbing, M. Donald Blaufox, Lorenzo C. Aschinberg, \\ Geraldine I. Silkalns, Jay Bernstein, Adrian Spitzer, and \\ Chester M. Edelmann, JR., with the technical assistance of \\ Theresa C. W. Liang \\ From the Departments of Pediatrics, Medicine, Radiology, and Pathology, and \\ The Rose F. Kennedy Center, Albert Einstein College of Medicine, Bronx, \\ New York 10461; and the Department of Anatomic Pathology, William \\ Beaumont Hospital, Royal Oak, Michigan 48072
}

A B S TRACT The intrarenal distribution of radionuclide microspheres injected into the thoracic aorta was used to examine glomerular blood flow distribution (GBFD) in 26 healthy, unanesthetized puppies, ranging in age from $5 \mathrm{~h}$ to 42 days, and in 5 adult dogs. For analysis, the cortex was divided into four equally thick zones designated zone I (subcapsular) to zone IV (juxtamedullary).

During the first $36 \mathrm{~h}$ of life, the highest flow rate was in zone II, which received $35.5 \pm 2.0 \% / \mathrm{g}$, compared with $26.8 \pm 1.4 \%$ to zone I, $23.7 \pm 1.4 \%$ to zone III, and $13.4 \pm$ $1.4 \%$ to zone IV. At age $6 \mathrm{wk}$, zone I had the highest rate of perfusion $(48.6 \pm 2.1 \%$, compared with $28.8 \pm 1.4 \%$ in zone II, $15.8 \pm 0.8 \%$, in zone III, and $6.8 \pm 0.6 \%$ in zone IV). The 6 -wk old animals resembled the adult animals, except for relatively greater perfusion per gram of zone $I$ in the former group. Changes in relative GBFD did not correlate with those in arterial pressure or peripheral hematocrit.

The distribution of glomeruli among the four zones of the cortex followed its own pattern of development. At birth and at $6 \mathrm{wk}$, the greatest density of glomeruli was in zone I $(50.6 \pm 5.4$ and $42.7 \pm 3.9 \% / \mathrm{g}$ respectively, as

This work was presented in part at the 5th Annual Meeting of the American Society of Nephrology, Washington, D. C., 22-23 November 1971.

Dr. Olbing was a recipient of a research and training scholarship by the Deutsche Forschungsgemeinschaft and Dr. Aschinberg was a fellow of the National Kidney Foundation.

Dr. Olbing's present address is 43 Essen, Klinikum, Department of Pediatric Nephrology, West Germany.

Received for publication 13 April 1973 and in revised form 11 June 1973. compared with $24.1 \pm 2.9 \%$ in adults); in adults zone II contained the greatest density $(39.1 \pm 1.6 \%)$.

At birth the relative perfusion of glomeruli in zone I was only one-fifth that of glomeruli in zone IV, with intermediate values in zones II and III. By $6 \mathrm{wk}$ of age, increased perfusion of the outer cortical glomeruli resulted in rates of flow in the four zones that did not differ significantly from each other. Relative perfusion in zone I continued to increase, so that in the adult animals perfusion in that zone was significantly greater than in the three deeper zones.

These data demonstrate the marked hemodynamic changes that take place within the kidney during the first few weeks of life. The relatively greater blood flow of the most deeply situated nephrons in the early postnatal period suggests ascendancy of this population of nephrons and may have important functional implications.

\section{INTRODUCTION}

A low rate of glomerular filtration in neonates as compared with adults has been documented in man (1-7), dog (8-10), guinea pig (11), monkey (12), rat (13-15), and sheep $(16,17)$. It has been shown in several species, including man and dog, that renal blood flow increases markedly during the first weeks of life $(4,14$, 18-22). Two lines of evidence suggest that in addition to the absolute increases in total renal blood flow and glomerular filtration rate, other hemodynamic changes within the kidney may be of considerable magnitude. Juxtamedullary glomeruli and their proximal tubules are morphologically more developed at birth than outer 
cortical glomeruli, since structural maturation proceeds from the inner cortex outward (23-26). Spitzer and Brandis (27) noted in guinea pigs that during the first 2 wk of life, during which time overall kidney filtration increased by an average of $0.96 \mathrm{nl} / \mathrm{min}$ per nephron, the single nephron filtration rate $(\mathrm{SGFR})^{1}$ of the superficial cortex increased by only $0.17 \mathrm{nl} / \mathrm{min}$, reflecting a more marked increase in the filtration rate of the deeper units. In contrast, during the next $2 \mathrm{wk}$, the increase in whole kidney filtration rate could be accounted for entirely by the change in SGFR in the outer cortex. Similarly, in puppies 21-69 days of age, Horster and Valtin (10) found a 7 -fold increase in SGFR of the superficial glomeruli, whereas the filtration rate of the whole kidney increased only approximately 4.5 -fold, reflecting the more rapid rate of change in the outer cortex of these somewhat older animals. These observations suggest that functional maturation, like structural maturation, proceeds from the inner toward the outer cortex.

Experiments designed to evaluate whether the centrifugal pattern of morphologic and functional maturation is paralleled by changes in intrarenal hemodynamics are few $(19,28)$. Accounting in part for this was the lack of a noninvasive method for the examination of intrarenal blood flow distribution in newborns. The present study was performed to investigate changes in the intracortical distribution of glomerular blood flow and in glomerular density in unanesthetized puppies during the first 6 wk of life, utilizing the radionuclide-labeled microsphere technique $(29,30)$.

\section{METHODS}

Healthy, pregnant mongrel dogs were acquired 1-2 wk before whelping and were fed commercial food (Quaker City Dog Food) supplemented by milk. 26 normally delivered, well-developed puppies, with a birth weight of at least $400 \mathrm{~g}$, were studied between $5 \mathrm{~h}$ and 42 days of age. During the first $4 \mathrm{wk}$ of life they were suckled exclusively. Later they were allowed to eat commercial food but were withheld from it for $12 \mathrm{~h}$ before an experiment. Suckling was available to all puppies until immediately before the experiments.

Microsphere technique. The catheterization, injection, and counting techniques were modified from the method developed by Milstein, Lee, Liang, and Blaufox for use in the rat (31). During surgery the animals were placed on a heating table with a constant temperature of $37^{\circ} \mathrm{C}$. Under ether anesthesia the aorta was cannulated via the antecubital artery or, if possible, a branch of it. The tip of a PE 10 catheter was tapered to approximately onehalf of its original diameter and was slightly curved to facilitate passing the right angle at the origin from the aorta, thus permitting placement of the catheter into the arch of the aorta, close to the root. In puppies scheduled for injections at a later age or for delayed examination, surgery was performed under sterile conditions. The anesthesia, kept as light as possible, lasted on the average for $20 \mathrm{~min}$. After

${ }^{1}$ Abbreviations used in this paper: GBFD, glomerular blood flow distribution; SGFR, single nephron filtration rate. awaking, the puppies were returned to their mother's care with the catheter in place.

$3-5 \mathrm{~h}$ after surgery, and if necessary after normalizing body temperature $\left(37-37.5^{\circ} \mathrm{C}\right)$, approximately 750,000 carbonized radionuclide-labeled microspheres with a mean diameter of $15 \pm 5 \mu \mathrm{m}$ were injected over a period of $5 \mathrm{~s}$. They were suspended in dextran and Tween 80 and were shaken vigorously for $5 \mathrm{~min}$ before injection. The injected volume ranged between 0.05 and $0.15 \mathrm{ml}$. After the injection the catheter was flushed immediately with $0.3-0.5$ $\mathrm{ml}$ of saline, after which it was removed and the vessel ligated. Intraaortic pressure and heart rate, determined during each study by a Statham transducer model P23 (Statham Instruments, Inc., Oxnard, Calif.) and a Grass model 5 polygraph recorder (Grass Instrument Co., Quincy, Mass.), were not influenced by the injection of the microspheres.

Studies in adult animals differed as follows. PE 20 catheters, instead of $\mathrm{PE} \mathrm{10,} \mathrm{were} \mathrm{placed} \mathrm{under} \mathrm{anesthesia} 2$ days before injection of microspheres. During the $12 \mathrm{~h}$ before this procedure, the dogs were fasted, but had free access to water. In all other respects the methods used in the adult animals were identical to that of the puppies.

The microspheres were labeled with ${ }^{141} \mathrm{Ce},{ }^{85} \mathrm{Sr}$, or ${ }^{51} \mathrm{Cr}$. The specific activity on receipt at the laboratory averaged $7 \mathrm{cpm}$ per microsphere for cesium, 13 for strontium, and 2 for chromium. The strontium, because of its long half-life, was used in all studies, including all those in which sacrifice was delayed for $6 \mathrm{wk}$. Because of the counting difficulties with chromium, this isotope was used soon after receipt in the laboratory, and was used only in the four animals in whom three injections of microspheres were made.

For the determination of the distribution of the microspheres within the kidney, the animals were deeply anesthetized, and both kidneys were removed and allowed to drain for several minutes, while blood was drawn from the aorta for determination of hematocrit, creatinine, and urea nitrogen. A midlongitudinal section, approximately $1.5 \mathrm{~mm}$ thick, was cut from each kidney. Four or five approximately $5-\mathrm{mm}$ broad segments with corticomedullary borderlines parallel to the surface were selected from each midsection, excluding medullary rays as carefully as possible (Fig. 1). The cortex was separated from the medulla just below the arcuate vessels, and was divided into four equally thick zones by cuts paralleling the outer surface and the corticomedullary borderline. The subcapsular area was designated zone I and the juxtamedullary cortex zone IV. A thin, superficial strip of medullary tissue also was obtained. All cutting was done by hand with razor blades. It was decided to section the cortex into four zones because McNay and Abe showed in adult dogs that four equal-sized zones of the cortex have different rates of perfusion, and that these can be changed to a remarkable degree under various conditions independently one from the other (32-35). This has been confirmed by another laboratory $(36,37)$. Thus, this method provides more information than examining only the outer two-thirds and the inner one-third of the cortex, as done in all previously published studies in puppies $(19,28,38)$. The separation of the cortex into more than four zones, as has been done in adult dogs $(39,40)$, is not applicable to the cortex of the newborn which is only $2-3 \mathrm{~mm}$ thick.

All kidneys had a normal appearance on the outer and cut surfaces, except one that was excluded from further examination after a macroscopic cortical scar was seen.

The corresponding slices of each area of each kidney were pooled, weighed, and their radioactivity measured over $30 \mathrm{~min}$ in a two-channel, well-scintillation counter (Tri- 
Carb scintillation spectrometer, model 3002, Packard Instrument Co., Inc., Downers Grove, Ill.). Absolute numbers of counts averaged approximately $50,000 / 30 \mathrm{~min}$ for ${ }^{141} \mathrm{Ce}$ and ${ }^{85} \mathrm{Sr}$, and approximately $10,000 / 30 \mathrm{~min}$ for ${ }^{51} \mathrm{Cr}$, representing a minimum of approximately 200 microspheres per sample. Defining the sum of the activities per gram of all four cortical zones as $100 \%$, the percentage of the total activity per gram was determined for each individual zone of cortex.

In two animals more than $3 \%$ of the total activity was found in the area designated medulla; this was considered as evidence of improper cutting, and these animals were excluded from further analysis. After injection of microspheres into the left renal artery $1.04 \%$ of the activity per gram of total left kidney was found per gram of randomly selected lung tissue; the activities in brain, heart, spleen, liver, right kidney, muscle, and skin did not exceed background.

Validation of methods. Reproducibility of the methodology was evaluated as follows. In 10 puppies and 5 adult dogs, two injections of differently labeled microspheres were performed with an interval of $5 \mathrm{~min}$. Identical distribution of both labels would yield ratios of relative activicy per zone of the two injections equal to unity. The mean ratios of all zones in each age group were not significantly different from one, and the standard errors were small.

For further validation of the methodology and demonstration of the reproducibility of the cutting technique, comparison was made between the left and the right kidney in each study. Again, the means of the ratios of the distribution of the microspheres were not significantly different from one, and the standard errors were small.

To detect a possible effect of prior injection of microspheres at an earlier age on the subsequent distribution of microspheres, comparison was made of eight puppies with one or two previous injections and four previously uninjected animals. The relative distribution of microspheres injected at 6 wk of age was identical in the two groups.

All puppies were studied under physiological conditions. They had normal values of urea-nitrogen and creatinine for their respective ages, and their kidneys appeared normal on macroscopic and microscopic examination. From each litter, two puppies were spared any experimental procedures and grew up without signs of disease. Other puppies were allowed to survive after surgery and injection of microspheres; they grew at the same rate as their siblings without surgical intervention, although growth of the foreleg was retarded as a consequence of the vascular ligation.

Greatest possible care was taken to avoid interference with normal conditions at the time of injection of microspheres. No sequelae of the previous light anesthesia were demonstrable. The puppies were well-acquainted with the investigators by daily visits and seemed to be completely relaxed during the injections. Pulse rate and mean systemic arterial pressure recorded at the time of injection were considered as normal for the respective ages, although there is some discrepancy with results reported from other laboratories. The higher average values found by Arango and Rowe immediately after catheterization of the aorta under local anesthesia may be explained by excitement (41). The average systemic arterial pressures of only $40 \mathrm{~mm} \mathrm{Hg}$ reported by Kleinman and Reuter (28) and Lubbe and Kleinman (42) were obtained from anesthetized puppies. Horster and Valtin report exceptionally high arterial pressures; their pure-bred beagles had mean values of approximately $80 \mathrm{~mm} \mathrm{Hg}$ (10) within the first 3 wk of life.

Histologic studies. Kidney tissue obtained from five animals randomly selected from each age group was fixed
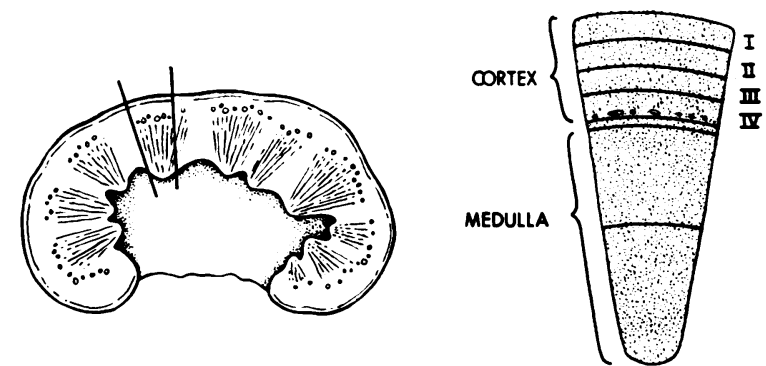

Figure 1 Technique of sectioning of the kidney. See text for details.

in $10 \%$ formalin, sectioned transversely across the long axis, and cut perpendicular to the surface. Microscopic sections were photographed at the highest magnification that allowed the complete thickness of the cortex to be included in the picture. The cortex in each photomicrograph was divided into four equally wide zones and the glomeruli counted. Glomeruli falling on lines dividing the cortical zones were assigned to the zone containing more than half the glomerulus; when a decision could not be reached by inspection, assignment was made by coin toss. Only completely developed glomeruli with Bowman's capsules were counted. Since glomerular number was counted in a single plane, the number of glomeruli per volume of each zone was determined by raising the actual count to the $3 / 2$ power. The relative distribution of glomeruli could then be calculated as (glomeruli per zone) $\div \Sigma$ (glomeruli per zone) $\mathrm{I}-\mathrm{IV} \times 100$.

Data from the right and left kidney of each animal were averaged for analysis. Statistical comparisons were made by analysis of variance. If the $F$ ratio was statistically significant, the difference between individual means was tested by Hartley's method of sequential analysis (43). Sets of data are expressed as the mean \pm SEM.

\section{RESULTS}

Renal histology. Except for an insignificant number of microspheres that appeared to be located in preglomerular arterioles, all had lodged in the glomerular capillaries. Only a few spheres were grouped in pairs; one triplet was found. All of the kidney tissue examined microscopically was normal, and no evidence of atrophy or other abnormality attributable to the microspheres could be found, even in puppies allowed to survive and grow for $6 \mathrm{wk}$ after injection.

Changes in glomerular blood flow distribution with age. From birth to $6 \mathrm{wk}$, the pattern of relative glomerular blood flow distribution (GBFD) per gram changed to a marked degree (Table I, Fig. 2). The most striking changes were found within the subcapsular cortex (zone I), where the percent of total cortical blood flow per gram increased from $26.8 \pm 1.4 \%$ to $48.6 \pm 2.1 \%$, a 1.8 -fold increase, and then declined to $37.1 \pm 2.6 \%$ in the adult animals. In all other cortical areas, a decrease from birth to $6 \mathrm{wk}$ of age was found in relative blood flow per gram, the relative perfusion in zone II at $6 \mathrm{wk}$ being $81 \%$ of that at birth, in zone III $67 \%$, and in 
TABLE I

Data From Puppies Injected at Various Ages and Examined 1 Day Later and Adult Dogs Injected and Examined 2 Days Later

\begin{tabular}{|c|c|c|c|c|c|c|c|c|c|c|c|c|}
\hline \multirow{3}{*}{$\begin{array}{c}\text { Animal } \\
\text { no. }\end{array}$} & \multirow{3}{*}{$\begin{array}{c}\text { Age at } \\
\text { time of } \\
\text { injection }\end{array}$} & \multirow{3}{*}{$\begin{array}{c}\text { Body } \\
\text { weight }\end{array}$} & \multirow{3}{*}{$\begin{array}{c}\text { Mean } \\
\text { arterial } \\
\text { pressure }\end{array}$} & \multirow{3}{*}{$\begin{array}{l}\text { Heart } \\
\text { rate }\end{array}$} & \multirow[b]{3}{*}{ Het } & \multirow{3}{*}{$\begin{array}{c}\text { Plasma } \\
\text { creatinine }\end{array}$} & \multirow[b]{3}{*}{ BUN } & \multirow{3}{*}{$\begin{array}{l}\text { Weight } \\
\text { both } \\
\text { kidneys }\end{array}$} & \multicolumn{4}{|c|}{ Glomerular blood flow distribution } \\
\hline & & & & & & & & & \multicolumn{4}{|c|}{ Cortex zone } \\
\hline & & & & & & & & & I & II & III & IV \\
\hline & & $k g$ & $m m \mathrm{Hg}$ & & $\%$ & \multicolumn{2}{|c|}{$\mathrm{mg} / 100 \mathrm{ml}$} & $g$ & \multicolumn{4}{|c|}{$\%$} \\
\hline 1 & $3 \mathrm{~h}$ & 0.47 & 47 & 178 & 41.5 & 0.5 & 28.6 & 6.27 & 31.2 & 35.1 & 21.2 & 12.5 \\
\hline 2 & $5 \mathrm{~h}$ & 0.42 & 50 & 192 & 42 & 0.6 & 35.6 & 6.18 & 25.9 & 36.5 & 24.8 & 12.8 \\
\hline 4 & $7 \mathrm{~h}$ & 0.46 & 43 & 182 & 41 & 0.4 & 27.4 & 5.07 & 24.5 & 34.5 & 25.1 & 15.8 \\
\hline 6 & $6 \mathrm{~h}$ & 0.46 & 39 & 170 & 42 & 0.7 & 27.4 & 6.80 & 25.9 & 46.2 & 16.9 & 11.1 \\
\hline 7 & $3 \mathrm{~h}$ & 0.41 & 45 & 176 & 40 & 0.5 & 28.6 & 7.04 & 31.3 & 34.0 & 25.8 & 8.9 \\
\hline 8 & $5 \mathrm{~h}$ & 0.43 & 31 & 174 & 46.5 & 0.4 & 27.4 & 8.05 & 32.9 & 24.4 & 17.5 & 25.1 \\
\hline 9 & $6 \mathrm{~h}$ & 0.50 & 46 & 166 & 42 & 0.5 & 35.6 & 7.93 & 22.7 & 27.4 & 32.1 & 11.2 \\
\hline 11 & $12 \mathrm{~h}$ & 0.45 & 48 & 168 & 43.5 & 0.7 & 26.5 & 5.93 & 25.1 & 35.7 & 24.9 & 14.2 \\
\hline 12 & $36 \mathrm{~h}$ & 0.50 & 45 & 172 & 32 & 0.7 & 26.5 & 6.09 & 29.3 & 38.1 & 21.7 & 10.9 \\
\hline 13 & $36 \mathrm{~h}$ & 0.40 & 54 & 176 & 26 & 0.8 & 25.2 & 5.82 & 19.1 & 42.8 & 26.8 & 11.1 \\
\hline 14 & 7 days & 0.82 & 60) & 160 & 28 & 0.7 & 26.5 & 10.90 & 34.9 & 34.4 & 20.9 & 9.8 \\
\hline 17 & 42 days & 3.15 & 65 & 168 & 24 & 0.6 & 19.2 & 28.46 & 39.9 & 34.2 & 15.6 & 10.3 \\
\hline 18 & 42 days & 2.40 & 56 & 170 & 24.5 & 0.55 & 6.6 & 20.40 & 53.8 & 25.6 & 16.4 & 4.2 \\
\hline 19 & 42 days & 2.25 & 76 & 156 & 26 & 0.65 & 19.9 & 24.52 & 46.4 & 25.8 & 20.8 & 7.0 \\
\hline 21 & 42 days & 3.60 & 64 & 186 & 25 & 0.9 & 20.2 & 31.86 & 52.9 & 22.5 & 15.4 & 9.2 \\
\hline 22 & 42 days & 3.50 & 81 & 172 & 23.5 & 0.9 & 17.1 & 29.35 & 39.2 & 34.3 & 17.3 & 9.2 \\
\hline 23 & 42 days & 1.75 & 84 & 150 & 23 & 0.55 & 20.2 & 20.17 & 52.8 & 31.2 & 11.6 & 4.4 \\
\hline 24 & 42 days & 2.25 & 64 & 176 & 25.5 & 0.45 & 6.4 & 24.20 & 34.7 & 38.6 & 21.3 & 5.9 \\
\hline 25 & 42 days & 4.00 & 68 & 168 & 25.0 & 0.4 & 19.1 & 32.38 & 52.1 & 25.9 & 15.6 & 6.4 \\
\hline 26 & 42 days & 2.75 & 80 & 146 & 24.0 & 0.45 & 20.0 & 27.35 & 58.5 & 23.4 & 13.1 & 5.0 \\
\hline 27 & 42 days & 3.15 & 76 & 160 & 24.5 & 0.3 & 7.7 & 28.88 & 48.2 & 31.5 & 11.9 & 8.4 \\
\hline 28 & 42 days & 2.30 & 65 & 170 & 27.0 & 0.5 & 14.7 & 22.79 & 52.2 & 26.4 & 16.4 & 4.7 \\
\hline 29 & 42 days & 2.45 & 82 & 148 & 25.5 & 0.55 & 20.0 & 21.38 & 52.7 & 26.1 & 14.2 & 7.0 \\
\hline 30 & Adult & 23.5 & 100 & 96 & 45.5 & 0.8 & 9.2 & 131.60 & 38.6 & 33.4 & 20.2 & 7.9 \\
\hline 31 & Adult & 27.1 & 115 & 104 & 42.0 & 0.65 & 13.7 & 107.55 & 46.0 & 32.3 & 16.3 & 5.6 \\
\hline 33 & Adult & 26.7 & 110 & 116 & 38.5 & 0.5 & 20.4 & 120.10 & 36.3 & 36.6 & 21.1 & 6.0 \\
\hline 34 & Adult & 24.3 & 100 & 104 & 47 & 0.4 & 10.1 & 118.60 & 30.8 & 33.7 & 23.8 & 11.8 \\
\hline 35 & Adult & 20.9 & 105 & 80 & 40.5 & 0.5 & 10.6 & 106.30 & 33.9 & 36.6 & 22.6 & 6.8 \\
\hline
\end{tabular}

zone IV $51 \%$. Statistically significant differences in relative GBFD were found between 6 -wk old and adult animals only in zone $\mathrm{I}$.

Changes in the relative location of labeled glomeruli during growth. 16 puppies were injected with microspheres within the first $36 \mathrm{~h}$ after birth. 10 were sacrificed and examined 1 day later, and 6 were allowed to survive and to grow for $6 \mathrm{wk}$ before they were sacrificed. Although the age at the time of injection and the technique of examination were identical, the relative distribution of the labeled glomeruli showed striking differences between the two groups (Fig. 3). The percentage of total activity per gram in the subcapsular cortex was only $3.0 \%$ when examination was deferred to permit a 6 -wk period of growth, as compared with $26.8 \%$ when examination was performed the day after injection. Only a slight difference was observed in zone II, whereas the percentages in zones III and IV were greater at $6 \mathrm{wk}$, by 1.7 - and 2.1 -fold, respectively.

A total of 27 puppies were sacrificed and examined at $6 \mathrm{wk}$ of age, after receiving microsphere injections at birth, 1, 3, or 6 wk of age (Fig. 4). Four animals had three injections, six had two injections, and two were injected only once. Of the glomeruli labeled at birth, only $3.0 \pm 0.33 \% / \mathrm{g}$ were located in cortex zone I 6 wk later, as compared with $24.8 \pm 2.1 \%$ of those labeled at 7 days of age, $41.7 \pm 7.9 \%$ of those labeled at 3 wk of age, and $48.6 \pm 2.1 \%$ of those labeled 1 day before examination at $6 \mathrm{wk}$. No differences were demonstrated in zone II in the relative percent of microspheres injected at various ages. However, the percentage of total activity per gram at 6 wk of age in zone III and IV was greater for microspheres injected within a few hours after birth than for those injected 1,3 , or $6 \mathrm{wk}$ later $(P=0.001)$. It should be noted that no differences were found in any zone between injections made at 21 or 42 days.

Changes of relative distribution of glomeruli per zone of cortex with age. The relative distribution of glomeruli in the cortex changed progressively from birth to $6 \mathrm{wk}$ of age and to adulthood (Table II). The outer cortical fraction (zone I) decreased by more than half, whereas the percentage of glomeruli per unit volume of zone III more than doubled. The fraction found in zones II and IV changed insignificantly.

The main reason for the marked change in the fractional distribution of glomeruli is the postnatal develop- 


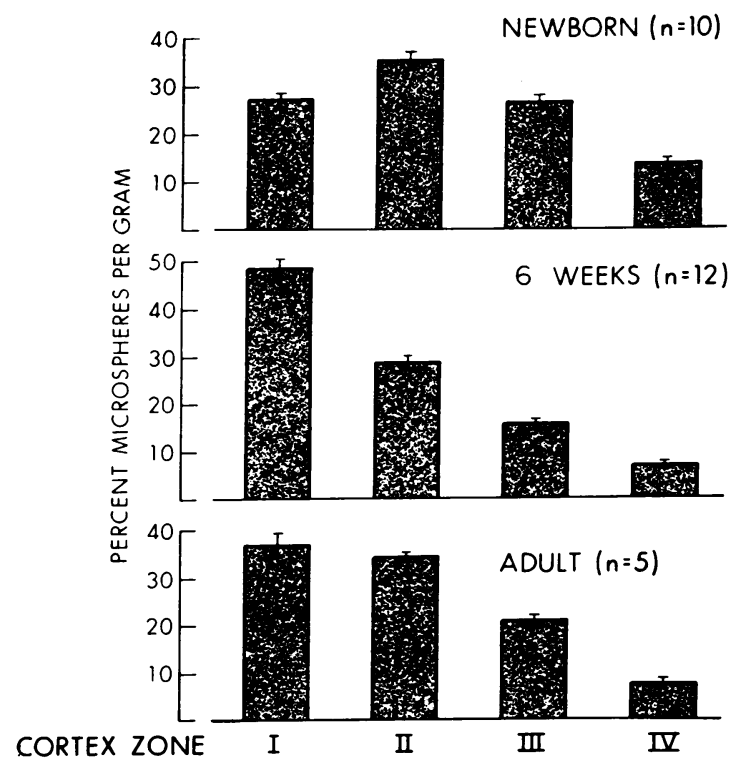

Figure 2 Relative glomerular blood flow per gram of tissue in three age groups. All animals were examined 1 or 2 days after injection of microspheres. Within each age group the differences between the means of the four zones are statistically significant $(P<0.05)$, except for zones I and II and I and III in the newborns and I and II in the adults. In zone I, the differences between the means of the three age groups are statistically significant $(P<0.05)$. No statistically significant differences are found in zone II. The only significant differences detected in zones III and IV are between the newborn and 6-wk old groups.

ment of an aglomerular area in the outer cortex, the cortex corticis, as shown in Fig. 5. Neogenesis of glomeruli, observed in the first days after birth, but in no case after the 1st wk of age, was confined to the outer cortex.

Changes of relative single glomerular perfusion with age. The relative perfusion of single glomeruli in each

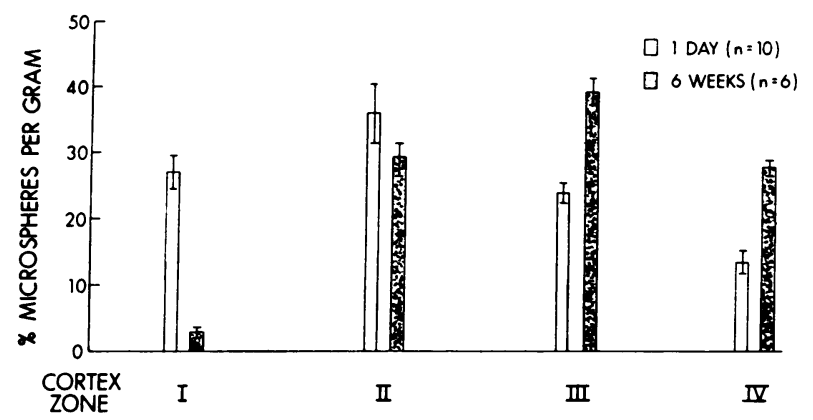

FIGURE 3 Relative distribution of microspheres injected 5-36 h after birth. The left bar of each pair represents animals examined within 1 day of injection; the right bar represents animals examined 6 wk later. The differences are significant; for zones I, III, and IV, $P<0.005$; for zone II, $P=0.1-0.05$.

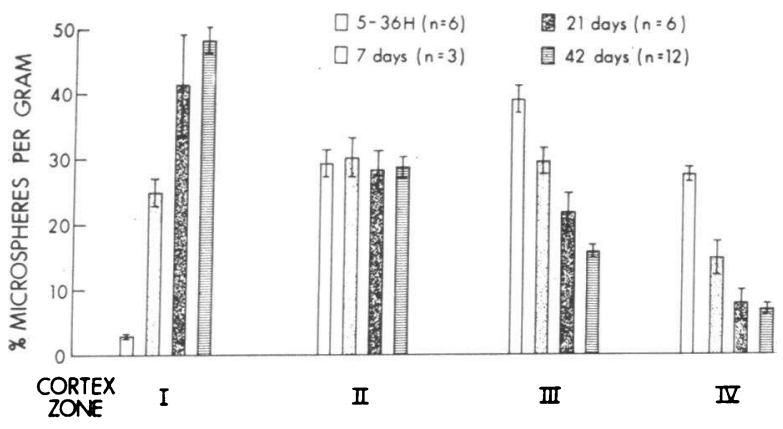

Figure 4 Relative distribution at 6 wk of age of microspheres injected at $5-36 \mathrm{~h}, 7,21$, or 42 days after birth. In zones I, III, and IV, the differences between the means are statistically significant $(P<0.05)$, except for the 21 and 42-day injections. No differences are observed in zone II.

zone of the cortex was determined from the percentage of total cortical flow per gram and the relative distribution of glomeruli (Fig. 6). The pattern of fractional perfusion per glomerulus showed even more marked differences between the three age groups than when expressed per gram of tissue. Between 5 and $36 \mathrm{~h}$ after birth, glomeruli in the inner cortex were perfused at a rate five times that of those in the outer cortex. In contrast, in 6-wk old puppies blood flow through glomeruli in the outer cortex was greater than in the deeper areas, with the pattern beginning to resemble that observed in the adult dog.

Changes of GBFD and arterial pressure. Mean systemic arterial pressure increased from $44.8 \pm 2.0 \mathrm{~mm} \mathrm{Hg}$ between 5 and $36 \mathrm{~h}$ after birth to $71.8 \pm 2.6 \mathrm{~mm} \mathrm{Hg}$ at 6 wk of age $(P<0.01)$. This value is still below that of $106 \pm 2.9 \mathrm{~mm} \mathrm{Hg}$ observed in the adult dogs $(P<0.01)$. At any given age, no correlation could be demonstrated between GBFD and systemic arterial pressure. As a

TABLE II

Relative Distribution of Glomeruli Per Cortical Zone

\begin{tabular}{|c|c|c|c|c|c|}
\hline Age & $n$ & Zone I & Zone II & Zone III & Zone IV \\
\hline Newborn & 5 & $\begin{array}{l}50.6 \\
(5.41)\end{array}$ & $\begin{array}{l}32.9 \\
(3.16)\end{array}$ & $\begin{array}{l}11.4 \\
(2.20)\end{array}$ & $\begin{array}{c}5.1 \\
(0.90\end{array}$ \\
\hline $6 \mathrm{wk}$ & 5 & $\begin{array}{l}42.7 \\
(3.94)\end{array}$ & $\begin{array}{l}33.3 \\
(3.17)\end{array}$ & $\begin{array}{l}17.8 \\
(2.01)\end{array}$ & $\begin{array}{l}6.2 \\
(0.95)\end{array}$ \\
\hline Adult & 5 & $\begin{array}{l}24.1 \\
(2.89)\end{array}$ & $\begin{array}{l}39.1 \\
(1.65)\end{array}$ & $\begin{array}{l}24.8 \\
(0.77)\end{array}$ & $\begin{array}{l}12.0 \\
(2.53)\end{array}$ \\
\hline$P$ & $\begin{array}{l}\text { Newborn vs. } \\
6 \text { wk } \\
\text { Newborn vs. } \\
\text { adult } \\
6 \text { wk vs. } \\
\text { adult }\end{array}$ & $\begin{array}{l}<0.05 \\
<0.05\end{array}$ & is & $0.05-0.1$ & is \\
\hline
\end{tabular}

Within each age group, the means of each zone are significantly different from each other $(P<0.05)$ except for the difference between III and IV in the newborn, $I$ and $I I$ at $6 \mathrm{wk}$, and $I$ and $I I I$ in the adults. 

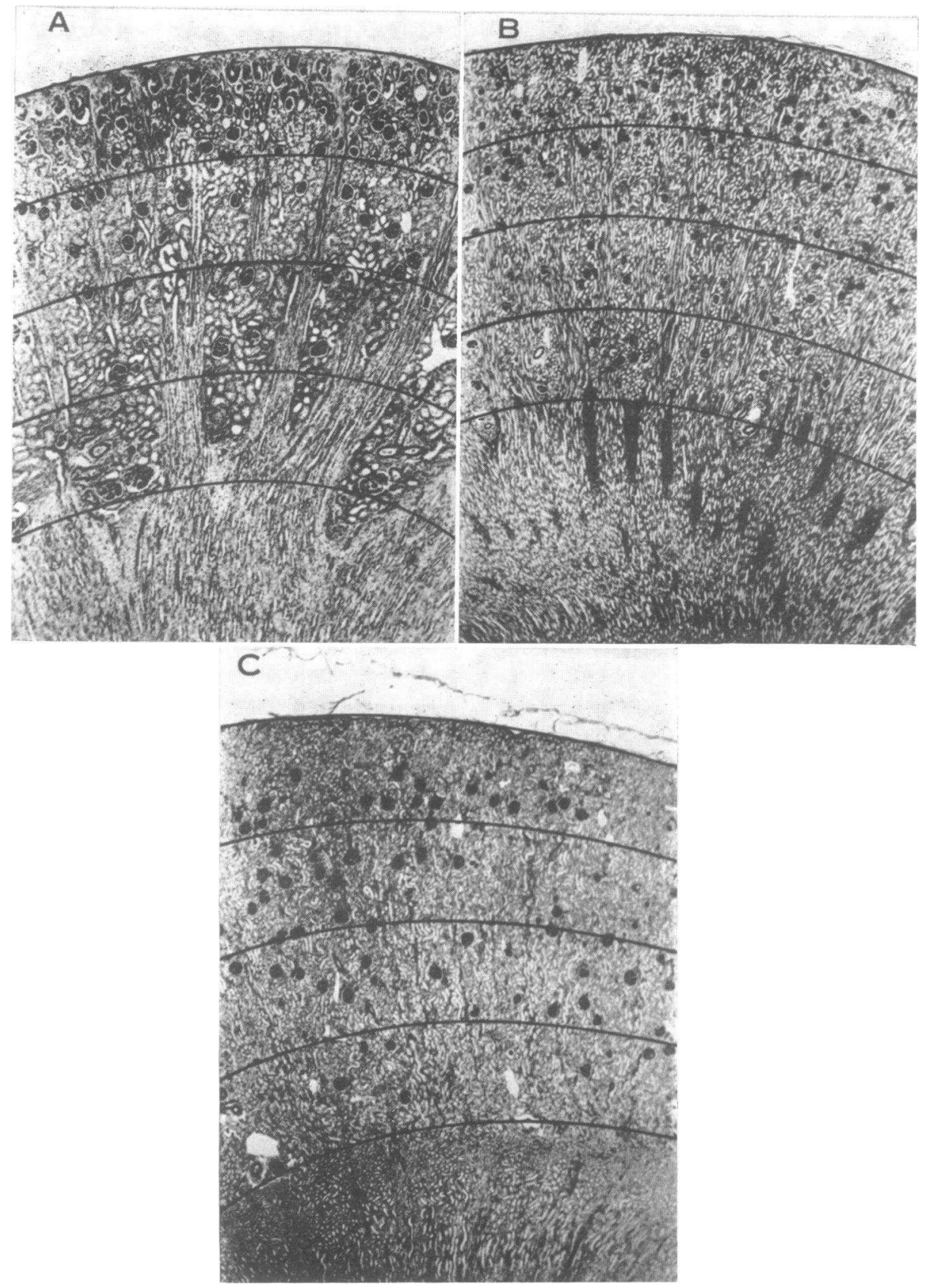

FIGURE 5 Photomicrographs of renal cortex, showing distribution of glomeruli. The cortex has been divided into four equal zones and the glomeruli counted in each. Nephrogenesis is still present at the time of birth (A), and glomeruli are very dense in the peripheral cortex. Differentiation of primitive metanephric vesicles from vascularized glomeruli is difficult and at times arbitrary. With increasing age and tubular growth, the glomeruli become more separated (B). There is also a "redistribution", in that an outer band of tubules, the cortex corticis, lies beneath the capsule. In newborns the glomeruli of the inner zone are perceptibly larger than in the outer zone (A), a difference that is gradually erased as the kidney grows (C). Hematoxylin and eosin stains. (A) Newborn pup, $\times 30$; (B) 6-wk old pup, $\times 12$; (C) adult dog, $\times 12$.

representative example, this lack of correlation is demonstrated for cortex zone I in Fig. 7; further details are presented in Table I.
Changes of GBFD and peripheral hematocrit. Mean peripheral hematocrit between 5 and $36 \mathrm{~h}$ after birth $(39.6 \pm 1.9 \%)$ was significantly greater than at 7 days 


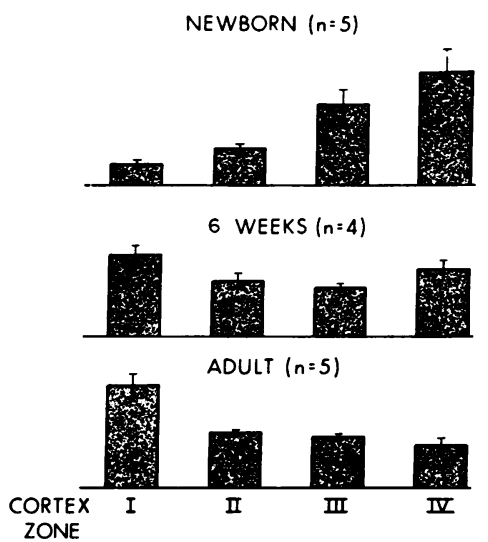

Figure 6 Relative blood flow per glomerulus in the four cortical zones. The figure is constructed so that the total height of the bars in each age group is equal. Differences between the newborn and 6-wk old animals are significant $(P<0.05)$ only for zone I. Differences between the newborn and adult animals are significant for zones I and IV. No statistically significant differences are detected between the 6-wk old and adult animals. In the newborn, differences between the zones are statistically significant except for I and II, and III and IV. In the 6-wk old group, none of the differences between the means is statistically significant. In the adult group, zone $I$ is significantly different from zones II, III, and IV. The other means do not differ significantly.

$(30.1 \pm 2.0 \%, P<0.01)$ and decreased further to $24.8 \pm$ $0.3 \%(P=0.001)$ at $6 \mathrm{wk}$ of age. Analysis at given ages failed to suggest any direct correlation with GBFD of individual puppies. From $6 \mathrm{wk}$ of age to adulthood, peripheral hematocrit increased markedly (to $42.7 \pm 1.6 \%$, $P<0.001$ ), although relative GBFD changed only slightly.

\section{DISCUSSION}

Microspheres with an average diameter of approximately $15 \mu \mathrm{m}$ lodge in glomerular capillaries without recirculation $(29,30,31,44)$, and after injection into the left ventricle or the root of the aorta, their distribution in the renal cortex reflects the GBFD at the time of injection. However, in comparison of the intrarenal distribution of antiglomerular basement membrane antibody with that of microspheres, Wallin, Rector, and Seldin $(45,46)$ concluded that, due to streaming, microspheres over-estimate plasma flow to the superficial cortex. Although the results of numerous studies in which microspheres have been employed must, therefore, be reconsidered, the authors who noted streaming (39) employed much thinner sections than those investigators who did not note streaming. It should be emphasized, however, that although sectioning of the cortex into only four sections, as done in the present study, may obscure streaming, this would not affect the directional changes with age that are demonstrated here.

It is well-established that maturation of the kidney fol- lows a centrifugal pattern, the deeper structures at any given age being more mature than those in more superficial regions. Spitzer and Brandis (27) have shown in guinea pigs that during the first few days of life the filtration rate in the outer cortical glomeruli is $1 / 10$ th that of the juxtamedullary glomeruli. Increase in total kidney glomerular filtration rate (GFR) with age was due to increase in the filtration rate of the deep nephrons during the first 2 wk of life, and subsequently to increase in the GFR of the superficial nephrons.

Moore, Satrasook, Fine, Katz, and Edelmann (47) provided data in support of the hypothesis that the low extraction of $P$-aminohippuric acid (PAH) by the immature kidney reflected a relatively large fraction of total renal blood flow perfusing the juxtamedullary nephrons and the vasa recta, thus bypassing a secretory site for PAH. The first direct evidence in support of this was presented by José et al. (19). Examination of the intrarenal distribution of blood flow in puppies $6-16 \mathrm{wk}$ of age, using the xenon-washout technique demonstrated a threefold increase in outer cortical flow. In contrast, inner cortical flow increased only slightly.

The data in the present study demonstrate for the first time the major changes that take place within the first few weeks of life in intrarenal distribution of blood flow throughout the cortex, and in relative blood flow per glomerulus, coincident with the period of rapid growth of nephrons and neogenesis of glomeruli in the outer cortex.

Originally it was planned to make serial injections of microspheres into the same animal, with sacrifice at $6 \mathrm{wk}$ of age, to determine the sequential pattern of

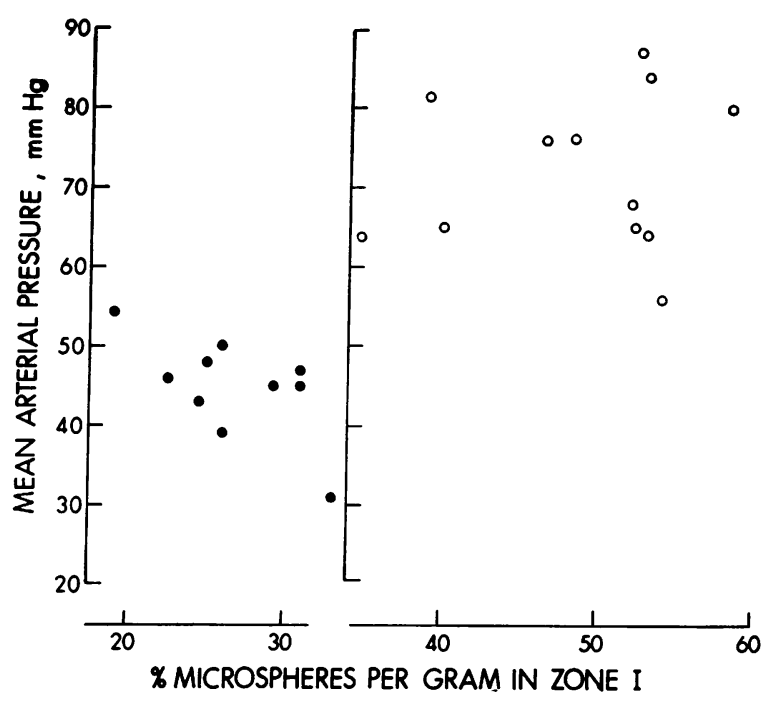

FIGURE 7 Relationship between mean arterial blood pressure and relative glomerular blood flow per gram of cortex zone I. Each point represents one animal, $3-36 \mathrm{~h}$ of age $(\bullet)$, or $6 \mathrm{wk}$ of age (O). Lack of correlation between flow and blood pressure is demonstrated. 
change in the same kidney. The results of such studies made it clear, however, that microspheres injected within the first days or weeks of life had shifted to relatively deeper positions when examined weeks later, due to the formation of new glomeruli in the outer cortex and to changes in the distribution of glomeruli within the cortex as a consequence of tubular growth and the development of an aglomerular subcapsular cortical zone. Injections of microspheres at various ages and examination at $6 \mathrm{wk}$ demonstrated that most of these changes took place during the 1st wk of life, with little additional change occurring after the 3 rd wk.

The marked increase that we observed during the first 6 wk of life in relative glomerular blood flow per gram of outer cortex (zone I) thus could have been due to formation of new glomeruli, or a relative increase in flow per glomerulus, due to growth of glomeruli or changes in vascular resistance. These possibilities were explored by determining histologically the percent of glomeruli in each zone in the newborn, at 6 wk of age, and in the adult. The major change observed was a decrease in the percent of glomeruli in the outermost cortex, due, as noted above, to the development of the cortex corticis. That these differential rates of growth are not completed by $6 \mathrm{wk}$ of age is shown by the differences in distribution of glomeruli found between the 6-wk old and the adult animals.

When the relative GBFD is factored by the relative distribution of glomeruli per zone, it becomes apparent that a marked increase in perfusion of the outer cortical glomeruli took place during the time period covered by the study. In the deepest zone of the cortex a relative decrease in flow per glomerulus took place, reflecting the ascendancy of the outer cortex by $6 \mathrm{wk}$ of age. However, blood flow to the most superficial glomeruli at 6 wk of age was only $20 \%$ greater than that of glomeruli in zone IV, and $50 \%$ greater than in zone II and these differences were not statistically significant. In contrast, the perfusion of the outer cortical glomeruli in the adult dog is almost double that of the glomeruli in zones II and III, and more than double that in IV.

Few other data are available concerning plasma flow in the superficial and juxtamedullary glomeruli. Källskog, Ulfendahl, and Wolgast (48), using a modified microsphere technique in rats, found perfusion of the outer cortical glomeruli to be $20 \%$ greater than the juxtamedullary glomeruli, a difference that was not statistically significant. Barratt, Wallin, Rector, and Seldin (49), using

'It is recognized that heterogeneity of nephrons within each zone of the cortex and the difficulty in differentiating perfused from nonperfused glomeruli gives this calculation only semiquantitative significance. Nevertheless, these data do serve to demonstrate the differences in glomerular blood flow in various levels of the cortex and the changes that take place with age. the antiglomerular basement membrane-antibody technique, found higher single-nephron plasma flow in the juxtamedullary cortex than in the superficial cortex of the hydropenic rat, with an accentuation of this difference following massive volume expansion. Using the same technique, however, Wallin et al. (45) found no differences in plasma flow in outer cortical, midcortical, and inner cortical glomeruli in hydropenic dogs.

In the present studies relative blood flow per glomerulus was found to be very low in the superficial cortex of newborn animals, and to increase progressively with age. Although total kidney blood flow was not determined, the values shown in Table III were calculated utilizing data obtained in other puppies studied in this laboratory (50). In this fashion the magnitude of change in blood flow per glomerulus throughout the cortex becomes apparent. From birth to 6 wk of age, the 20 -fold increase in renal blood flow per kidney was associated with only a 4-fold increase in blood flow in the deep glomeruli (zone III and IV), but a greater than 10 -fold increase in the glomeruli of zone II, and a 25 -fold increase in zone I. Examined in another way, $60 \%$ of the increase in kidney blood flow took place in zone I, with less than $5 \%$ being contributed by zone IV. Since these changes greatly exceed the increase in size of glomeruli, it is apparent that local changes in glomerular vascular resistance must have taken place. Although, as shown in Fig. 6, the pattern of blood flow distribution at age $6 \mathrm{wk}$ resembles that of the adult kidney, the magnitude of the quantitative change still to occur is apparent.

The mechanism ( $\mathrm{s}$ ) controlling the distribution of blood within various segments of the cortex remains to be elucidated. No correlation was found in the present study between changes in distributional flow and either peripheral hematocrit $(51,52)$ or blood pressure $(28)$. It may be of significance that peripheral renin levels in the neonate are high (53). Additionally the role of the sympathetic nervous system has been studied by José et al. (54), who concluded that the pattern of intrarenal blood flow distribution may be due to a high level of alpha adrenergic activity.

Finally, comment should be made of the possible functional significance of these marked hemodynamic changes. The existence of two functionally dissimilar populations of nephrons in the outer and inner cortex of the adult animal has been commented on recently by Jamison (55). It is recognized that the neonate responds in a limited fashion to salt loading, a phenomenon that may reflect the extreme immaturity and low level of filtration of the outer cortical nephrons (56). In contrast, diluting capacity and the ability to respond to a water load are relatively well-developed, reflecting the more mature functional level of the deep nephrons (56). It is likely that 
TABLE III

Changes with Age in Kidney Size, Nephron Number, Glomerular Distribution, and Blood Flow

\begin{tabular}{|c|c|c|c|c|c|c|}
\hline \multirow[b]{2}{*}{ Zone } & \multirow[b]{2}{*}{ Weight } & \multicolumn{2}{|c|}{ Glomerular no. } & \multicolumn{3}{|c|}{ Blood flow } \\
\hline & & total & per gram & per glom. & per gram & total \\
\hline & $g$ & & & $n l / \min$ & $\mathrm{ml} / \mathrm{min}$ & $m l / m i n$ \\
\hline \multicolumn{7}{|l|}{ Newborn } \\
\hline Cortex I & 0.766 & 175,136 & 228,636 & 3 & 0.686 & 0.525 \\
\hline II & 0.617 & 91,722 & 148,658 & 5 & 0.743 & 0.459 \\
\hline III & 0.481 & 24,777 & 51,511 & 11 & 0.566 & 0.272 \\
\hline IV & 0.363 & 8,365 & 23,044 & 16 & 0.369 & 0.134 \\
\hline Whole kidney & 3.26 & 300,000 & - & - & 0.426 & 1.39 \\
\hline \multicolumn{7}{|l|}{$6 \mathrm{Wk}$} \\
\hline Cortex I & 2.70 & 194,807 & 72,150 & 79 & 5.70 & 15.39 \\
\hline II & 2.31 & 129,977 & 56,268 & 53 & 2.98 & 6.89 \\
\hline III & 1.94 & 58,349 & 30,077 & 47 & 1.41 & 2.74 \\
\hline IV & 1.61 & 16,867 & 10,476 & 65 & 0.68 & 1.10 \\
\hline Whole kidney & 12.6 & 400,000 & - & - & 2.07 & 26.12 \\
\hline \multicolumn{7}{|l|}{ Adult } \\
\hline Cortex I & 15.8 & 125,164 & 7,922 & 822 & 6.51 & 102.9 \\
\hline II & 12.8 & 164,501 & 12,852 & 444 & 5.71 & 73.0 \\
\hline III & 10.1 & 82,333 & 8,152 & 420 & 3.42 & 34.6 \\
\hline IV & 7.1 & 28,001 & 3,944 & 350 & 1.38 & 9.8 \\
\hline Whole kidney & 58.4 & 400,000 & - & 一 & 3.77 & 220.3 \\
\hline
\end{tabular}

The weight of each zone is calculated according to the method of McNay and Abe (32), assuming the kidney to have the shape of an ellipsoid. Although this method has serious limitations, they do not affect the conclusions drawn from the derived data. Glomerular number per gram of cortex is calculated from the data of relative glomerular distribution (RGD) shown in Table II (see footnote) and the weight of each zone, as follows. Let $\mathrm{G}_{\mathrm{IV}}$ be the number of glomeruli per gram of zone IV, and $W_{I V}$ be the weight of zone IV. It then follows that,

$$
\begin{aligned}
\mathrm{G}_{\mathrm{I}} & =\mathrm{G}_{\mathrm{IV}} \times \mathrm{RGD}_{\mathrm{I}} / \mathrm{RGD}_{\mathrm{IV}} \\
\mathrm{G}_{\mathrm{II}} & =\mathrm{G}_{\mathrm{IV}} \times \mathrm{RGD}_{\mathrm{II}} / \mathrm{RGD}_{\mathrm{IV}} \\
\mathrm{G}_{\mathrm{III}} & =\mathrm{G}_{\mathrm{IV}} \times \mathrm{RGD}_{\mathrm{III}} / \mathrm{RGD}_{\mathrm{IV}} \\
\text { and } & \\
\mathrm{G}_{\mathrm{I}} \mathrm{W}_{\mathrm{I}} & +\mathrm{G}_{\mathrm{II}} \mathrm{W}_{\mathrm{II}}+\mathrm{G}_{\mathrm{III}} \mathrm{W}_{\mathrm{III}}+\mathrm{G}_{\mathrm{IV}} \mathrm{W}_{\mathrm{IV}}=\text { total glomerular number. }
\end{aligned}
$$

By substituting equations (1)-(3) in (4), using appropriate values of RGD, and assuming total glomerular number of 300,000 per kidney in the newborn and 400,000 per kidney for the older animals, (4) is solved for glomerular number per gram of zone IV. Glomerular numbers for the other zones are then readily calculated. Blood flow data are derived in a similar fashion, using the calculated glomerular number per zone and the data for relative glomerular perfusion, as shown in Fig. 7 . Renal blood flow per kidney is based on unpublished data from this laboratory.

as more data are obtained concerning the differential rates of development of the cortex, other functional characteristics of the immature kidney will be elucidated.

\section{ACKNOWLEDGMENTS}

The authors wish to thank Sylvia M. Wassertheil-Smoller, Ph.D., for help and advice with the statistical analyses, and they acknowledge the excellent secretarial assistance of Mrs. Jean Massaro.

This work was supported in part by U. S. Public Health Service Grants AM 14,877, HL 5267, and HL 11,984; The Health Research Council of the City of New York, Inc., I-605; and The Sylvan League, Inc.

\section{REFERENCES}

1. Barnett, H. L. 1940. Renal physiology in infants and children. I. Method for estimation of glomerular filtration rate. Proc. Soc. Exp. Biol. Med. 44: 654.

2. McCance, R. A., and W. F. Young. 1941. The secretion of urine by newborn infants. J. Physiol. (Lond.). 99: 265.

3. Dean, R. F. A., and R. A. McCance. 1947. Inulin, diodone, creatinine and urea clearance in newborn infants. J. Physiol. (Lond.). 106: 431.

4. Rubin, M. I., E. Bruck, and M. Rapoport. 1949. Maturation of renal function in childhood. Clearance studies. J. Clin. Invest. 28: 1144.

5. Weil, W. B., Jr. 1955. Evaluation of renal function in infancy and childhood. Am. J. Med. Sci. 229: 678 . 
6. West, J. R., H. W. Smith, and H. Chasis. 1948. Glomerular filtration rate, effective renal blood flow, and maximal tubular excretory capacity in infancy. J. Pediatr. 32: 10 .

7. Barnett, H. L., W. K. Hare, H. McNamara, and R. S. Hare. 1948. Influence of postnatal age on kidney function of premature infants. Proc. Soc. Exp. Biol. Med. 69: 55.

8. Dicker, E. E. 1952. Effect of diuretics in new-born rats and puppies. J. Physiol. (Lond.). 118: 384.

9. Heller, J., and K. Capek. 1965. Changes in body water compartments and inulin and $\mathrm{PAH}$ clearance in the dog during postnatal development. Physiol. Bohemoslov. $14: 433$.

10. Horster, M., and H. Valtin. 1971. Postnatal development of renal function: micropuncture and clearance studies in the dog. J. Clin. Invest. 50: 779.

11. Boylan, J. W., E. P. Colbourn, and R. A. McCance. 1958. Renal function in the foetal and new-born guinea pig. J. Physiol. (Lond.). $141: 323$.

12. Chez, R. A., F. G. Smith, and D. C. Hutchinson. 1964. Renal function in the intrauterine fetus. I. Experimental technique: rate of formation and chemical composition of urine. Am. J. Obstet. Gynecol. 90: 128.

13. Falk, G. 1955. Maturation of renal function in rats. Am. J. Physiol. 181 : 157.

14. Horster, M., and J. E. Lewy. 1970. Filtration fraction and extraction of $\mathrm{PAH}$ during neonatal period in the rat. Am. J. Physiol. 219: 1061.

15. Potter, D., A. Jarrah, J. Sakai, J. Harrah, and M. A. Holliday. 1969. Character of function and size in kidney during normal growth of rats. Pediatr. Res. 3 : 51.

16. Alexander, D. P., and D. A. Nixon. 1962. Plasma clearance of p-aminohippuric acid by the kidneys of foetal, neonatal and adult sheep. Nature (Lond.). 194: 483.

17. Alexander, D. P., and D. A. Nixon. 1963. Reabsorption of glucose, fructose, and mesoinositol by the foetal and post-natal sheep kidney. J. Physiol. (Lond.). 167: 480.

18. Calcagno, P. L., and M. I. Rubin. 1963. Renal extraction of para-aminohippurate in infants and children. J. Clin. Invest. 42 : 1632.

19. José, P. A., A. G. Logan, L. M. Slotkoff, L. S. Lilienfield, P. L. Calcagno, and G. M. Eisner. 1971. Intrarenal blood flow distribution in canine puppies. Pediatr. Res. 5 : 335.

20. Alexander, D. P., and D. A. Nixon. 1961. The foetal kidney. Br. Med. Bull. 17: 112 .

21. Oh, W., M. A. Oh, and J. Lind. 1966. Renal function and blood volume in newborn infant related to placental transfusion. Acta Paediatr. Scand. 55: 197.

22. Gruskin, A. B., C. M. Edelmann, Jr., and S. Yuan. 1970. Maturational changes in renal blood flow in piglets. Pediatr. Res. 4 : 7.

23. Peter, K. 1927. Untersuchungen über Bau und Entwicklung der Niere. Gustav Fischer, Jena, East Germany. 2nd volume.

24. Potter, E. L., and S. T. Thierstein. 1943. Glomerular development in the kidney as an index for fetal maturity. J. Pediatr. 22 : 695.

25. Ljundquist, A. 1963. Fetal and postnatal development of intrarenal arterial pattern in man. A micro-angiographic and histologic study. Acta Paediatr. 52: 443.

26. Fettermann, G. H., N. A. Shuplock, F. J. Philipp, and H. S. Gregg. 1965. The growth and maturation of human glomeruli and proximal convolutions from term to adulthood. Studies by microdissection. Pediatrics. 35 : 601.

27. Spitzer, A., and M. Brandis. 1972. Superficial nephron and total kidney glomerular filtration rate during development. Pediatr. Res. 6: 416.

28. Kleinman, L. I., and J. H. Reuter. 1973. Maturation of glomerular blood flow distribution in the new-born dog. J. Physiol. (Lond.). 228: 91.

29. Rudolph, A. M., and M. A. Heymann. 1967. The circulation of the fetus in utero. Methods for studying distribution of blood flow, cardiac output and organ blood flow. Circ. Res. 21 : 163.

30. Wagner, H. N., Jr., B. A. Rhodes, Y. Sasaki, and J. P. Ryan. 1969. Studies of the circulation with radioactive microspheres. Invest. Radiol. $4: 374$.

31. Milstein, D. M., H. B. Lee, T. Liang, and M. D. Blaufox. 1972. Glomerular blood flow distribution in the rat. Preliminary observations. In Radionuclides in $\mathrm{Ne}$ phrology. M. D. Blaufox, and J.-L. Funk-Brentano, editors. Grune \& Stratton, Inc., New York. 17.

32. McNay, J. L., and Y. Abe. 1970. Pressure-dependent heterogeneity of renal cortical blood flow in dogs. Circ. Res. 27 : 571.

33. McNay, J. L., and Y. Abe. 1970. Redistribution of cortical blood flow during renal vasodilitation in dogs. Circ. Res. 27: 1023.

34. McNay, J. L., and Y. Abe. 1970. Effects of acute and chronic salt loading on the distribution of renal cortical blood flow. Clin. Res. 18: 510. (Abstr.)

35. Miyazaki, M., and J. McNay. 1971. Redistribution of renal cortical blood flow during ureteral occlusion and renal constriction. Proc. Soc. Exp. Biol. Med. 138: 454

36. Stein, J. H., T. F. Ferris, J. E. Huprich, T. C. Smith, and R. W. Osgood. 1971. Effect of renal vasodilatation on the distribution of cortical blood flow in the kidney of the dog. J. Clin. Invest. 50: 1429.

37. Bay, W. H., J. H. Stein, J. B. Rector, R. W. Osgood, and T. F. Ferris. 1972. Redistribution of renal cortical blood flow during elevated ureteral pressure. $A m$. J. Physiol. 222: 33.

38. José, P., L. Slotkoff, L. Lilienfield, S. Counts, P. Calcagno, and G. Eisner. 1971. Adrenergic activity and salt excretion. Clin. Res. 19: 534. (Abstr.)

39. Katz, M. A., R. C. Blantz, F. C. Rector, Jr., and D. W. Seldin. 1971. Measurement of intrarenal blood flow. I. Analysis of microsphere method. Am. J. Physiol. 220: 1903.

40. Blantz R. C., M. A. Katz, F. C. Rector, Jr., and D. W. Seldin. 1971. Measurement of intrarenal blood flow. II. Effect of saline diuresis in the dog. Am. J. Physiol. 220: 1914

41. Arango, A., and M. I. Rowe. 1971. The neonatal puppy as an experimental subject. Biol. Neonate. 18: 173.

42. Lubbe, R. J., and L. I. Kleinman. 1969. Relationship between GFR and blood pressure in newborn puppies. Physiologist. 12 : 289.

43. Snedecor, G. W. 1956. Statistical Methods Applied to Experiments in Agriculture and Biology. Iowa State University Press, Ames.

44. Slotkoff, L. M., A. Logan, P. José, J. D'Avella, and G. M. Eisner. 1971. Microsphere measurement of intrarenal circulation of the dog Circ. Res. 28: 158.

45. Wallin, J. D., F. C. Rector, Jr., and D. W. Seldin. 1971. Measurement of intrarenal plasma flow with antiglomerular basement-membrane antibody $\mathrm{Am}$. J. Physiol. 221 : 1621. 
46. Wallin, J. D., F. C. Rector, Jr., and D. W. Seldin. 1972. Effect of volume expansion on intrarenal distribution of plasma flow in the $\operatorname{dog} \mathrm{Am}$. J. Physiol. 223: 125.

47. Moore, E. S., S. S. Satrasook, B. P. Fine, M. C. Katz, and C. M. Edelmann, Jr. 1969. Renal PAH extraction in puppies. 39th Annual Meeting of the Society of Pediatric Research, Atlantic City, N. J., 2, 3 May. 114. (Program and Abstr.)

48. Källskog, Ö., H. R. Ulfendahl, and M. Wolgast. 1972. Single glomerular blood flow as measured with carbonized ${ }^{141} \mathrm{Ce}$ labelled microspheres. Acta Physiol. Scand. $85: 408$.

49. Barratt, L. J., J. D. Wallin, F. C. Rector, Jr., and D. W. Seldin. 1973. Influence of volume expansion on single-nephron filtration rate and plasma flow in the rat. Am. J. Physiol. 224 : 643.

50. Aschinberg, L. C., D. I. Goldsmith, H. Olbing, M. A. Hardy, A. Spitzer, C. M. Edelmann, Jr., and M. D. Blaufox. 1973. Neonatal changes in renal blood flow distribution in puppies. Pediatr. Res. $7: 183$. (Abstr.)
51. Nashat, F. S., and R. W. Portal. 1967. The effects of changes in haematocrit on renal function. J. Physiol. (Lond.). 193: 513.

52. Schrier, R. W., and L. E. Earley. 1970. Effects of acute changes of hematocrit on renal hemodynamics and sodium excretion in hydropenic and volume-expanded dogs. J. Clin. Invest. 49: 1656.

53. Kotchen, T. A., A. L. Strickland, T. W. Rice, and D. R. Walters. 1972. A study of the renin-angiotensin system in newborn infants J. Pediatr. 80: 938.

54. José, P. A., A. Logan, L. M. Slotkoff, L. S. Lilienfield, P. L. Calcagno, and G. M. Eisner. 1972. Intrarenal blood flow distribution in the maturing kidney. In Radionuclides in Nephrology. M. D. Blaufox, and J.-L. Funck-Brentano, editors. Grune \& Stratton, Inc., New York 87.

53. Jamison, R. L. 1973. Intrarenal heterogeneity. The case for two functionally dissimilar populations of nephrons in the mammalian kidney. Am. J. Med. 54: 281.

56. Nash, M. A., and C. M. Edelmann, Jr. 1973. The developing kidney. Immature function or inappropriate standard. Nephron. $11: 71$. 